\title{
Justiça e direitos humanos na filosofia do direito de Emmanuel Lévinas
}

\author{
Justice and human rights in the philosophy of law by \\ Emmanuel Levinas
}

Marcio Renan Hamel ${ }^{*}$

Universidade de Passo Fundo, Passo Fundo, RS, Brasil

\section{Resumo}

A presente pesquisa apresenta uma reconstrução hermenêutica do conceito de justiça presente na filosofia de Emmanuel Lévinas, tal como aparece em alguns de seus escritos. Para cumprir a tarefa anunciada, analisa-se inicialmente a relação entre responsabilidade e justiça, considerando o reconhecimento do outro pela consciência moral, aparecendo, então a justiça. Em segundo lugar, investiga-se o entendimento levinasiano acerca dos direitos humanos, considerando a ideia de direitos do outro homem, em clara inversão à concepção tradicional desses direitos. Finalmente, o estudo valoriza a contribuição de Emmanuel Lévinas à filosofia do direito contemporânea, no sentido da necessidade de uma reconstrução epistêmica da teoria da justiça e dos direitos do homem.

Palavras-chave: Direitos Humanos. Justiça. Responsabilidade. 


\section{Abstract}

The present research presents a hermeneutic reconstruction of the concept of justice present in the philosophy of Emmanuel Lévinas, as it appears in some of his writings. To fulfill the task announced, the relationship between responsibility and justice is initially analyzed, considering the recognition of the other by the moral conscience, appearing, then, the justice. Secondly, it is investigated the Levinasian understanding of human rights, considering the idea of the rights of the other man, in a clear inversion of the traditional conception of these rights. Finally, the study values the contribution of Emmanuel Lévinas to the contemporary law philosophy, in the sense of the need for an epistemic reconstruction of the theory of justice and human rights.

Keywords: Human Rights. Justice. Responsibility.

\section{Introdução}

Da mesma forma que muitos temas abordados na vasta e complexa obra de Emmanuel Lévinas, a justiça e os direitos humanos também foram tratados pelo filósofo lituano. No entanto, ele não trouxe ao público uma obra específica sobre a discussão da justiça ou daqueles direitos, assim como Aristóteles que também não dedicou espaço peculiar para a reflexão acerca do justo ou como parte da tradição filosófica. Lévinas, por outro lado, dedicou um ou outro espaço de sua reflexão filosófica a esta categoria. $\mathrm{O}$ objetivo da presente pesquisa é buscar demonstrar qual foi este espaço, bem como a maneira pela qual Lévinas pensou a ideia de justiça.

A tarefa de averiguar a forma pela qual Emmanuel Lévinas aborda a questão da justiça, dos direitos humanos e até mesmo do Estado de Direito não é simples, pois o filósofo aborda esses temas de forma desordenada em algumas de suas obras, de maneira a apresentar reflexões esparsas e não pontuais. Deve-se, no entanto, levar-se em consideração que Lévinas é o filósofo do outro, da alteridade, e não necessariamente um pensador de filosofia do direito ou política, mas ao tratar 
da questão do ser-para-o-outro, embora mergulhado na fenomenologia de Husserl e na ontologia de Heidegger, aproxima-se muito de uma filosofia social e política ao mesmo tempo em que de uma filosofia do direito, até porque defende que sua teoria é uma ética da ética.

A presença da fenomenologia na filosofia de Lévinas é um traço bem marcante, pois é notável a forte influência em seus textos tanto de Husserl quanto de Heidegger. Precisamente a fenomenologia de Husserl trabalha com a promoção da ideia de "horizonte": foi "A partir de Husserl que a metáfora do horizonte se converteu em um importante estímulo para o pensamento" (GARCÍA, 1996, p. 222).

Heidegger também advertiu em Ser e Tempo que "nem sequer temos noção do horizonte desde o qual devemos capturar e fixar o sentido" (2000, p. 25). Dessa forma, segundo García (1996, p. 222), haverá de proporcionar também o jurista um horizonte para que possa ver e se deslocar. Fazer o jurista sair do seu enclausuramento para que possa respirar. Aí o horizonte se apresenta enquanto dimensão de infinito, mas o infinito não será um objeto de conhecimento, senão desejo: "A ideia de infinito é desejo" (LÉVINAS, 2012, p. 53).

No entanto, mesmo considerando a forte presença fenomenológica em sua obra, Lévinas conduz seu pensamento em clara oposição às análises de Husserl, pois o outro não é um alter ego, não é um de dois, senão um entre dois que jamais poderá ser subsumido em uma relação simétrica, opondo-se também a Heidegger no que diz respeito ao outro que aparece em situação recíproca de igualdade de um com outro (Miteinandersein), onde entende que um não é igual ao outro (HERNÁNDES, 2000, p. 248). Para Lévinas, um é diferente do outro, não havendo a relação de igualdade pretendida por Heidegger.

Dessa maneira, a fim de buscar refletir e apresentar o tema em questão optou-se pela escolha de algumas obras de Emmanuel Lévinas, cujo recorte leva a uma possibilidade de compreensão dos temas abordados, bem como de literatura secundária sobre o assunto. A partir dessa perspectiva, os conceitos são trabalhados, basicamente, a partir de três obras de Lévinas em sua respectiva ordem de cronologia original, quais 
sejam, Totalidade e Infinito (1988), Ética e Infinito (1988) e Entre Nós (1997)1. O texto conta também com a entrevista concedida a Angelo Bianchi em Paris, no ano de 1985, mas publicada tardiamente pelo próprio Lévinas em Alteridade e Transcendência e em Violência do Rosto (2010).

Para dar conta da investigação ora anunciada, o texto apresenta três seções temáticas, sendo a primeira seção uma análise acerca dos conceitos de responsabilidade e de justiça. Por intuitivo, o próprio subtítulo da seção dá a ideia de que o conceito de justiça decorre do conceito de responsabilidade pelo outro. Daí a necessidade de percorrer a reflexão levinasiana de ser-para-o-outro, quando o surgimento da consciência moral autoriza o aparecimento da ideia de justiça em sua obra. A segunda seção aborda a compreensão que Lévinas tem dos direitos humanos, os quais ele denomina de direitos do homem, sendo os mesmos uma exigência além da própria justiça.

Em artigo escrito sobre a alteridade e o infinito, Francisco Hernández (2000, p. 243) coloca a pergunta pela possibilidade de haver poesia após Auschwitz. De certa forma, também se pode perguntar pela possibilidade de haver filosofia após Auschwitz e, ainda mais, justiça. Os escritos de Emmanuel Lévinas provam que sim, desmentindo a assertiva do acerto de contas de Adorno com uma razão incapaz e falida ao longo do século XX.

\section{Da responsabilidade à justiça}

Em que pese Lévinas afastar-se da tradição filosófico-política, em Totalidade e Infinito (2015, p. 72) argumenta que justificar a liberdade humana não é demonstrá-la, mas sim torná-la justa. Nesse contexto, opõe uma crítica à teoria política ao assegurar que esta retira da justiça o valor da espontaneidade, da qual é preciso assegurar o completo exercício, ao harmonizar a liberdade própria com a liberdade dos outros.

1 As datas informadas se referem aos anos em que as obras foram publicadas no Brasil respectivamente. Optou-se por seguir a cronologia de origem, que no original corresponde à seguinte forma: a) Totalité et infini. Essai sur l'extériorité. La Haye: Martinus Nijhoff, 1961; c) Ethique et infini. Dialogues avec Philippe Nemo. Paris: Librairie Arthème Fayard et Radio France, 1982; d) Entre nous. Essais sur le penser-à-l'autre. Paris: Grasset \& Fasquelle, 1991. 
Pensar a justiça é um exercício de atrevimento que exige do jurista pensar por meio de duras tensões, posição desmedida que faz da introdução ao Direito um exercício de exaustão, cujo objetivo não é outra coisa senão perturbar a paz do jurista com ideias descabidas (GARCÍA, 1996, p. 221).

Ensina Lévinas que "outrem não é inicialmente feito, não é obstáculo, não ameaça de morte. [...] A ideia do perfeito não é ideia, mas desejo. É o acolhimento de Outrem, o começo da consciência moral, que põe em questão a minha liberdade" (2015, p. 73). Note-se que Lévinas argumenta nesse caso que para pensar o infinito é necessário transpormo-nos além de nós mesmos; por isso não se pode considerar o outro como objeto, é preciso desejá-lo e por ele ser responsável. Este é o fato de a consciência moral acolher a outrem, reconhecê-lo.

Ora, para Lévinas o acolhimento de outrem é o começo da consciência moral, que coloca em questão a minha liberdade. Contrariamente a Heidegger, que subordina a relação com outrem à ontologia, Lévinas vê na justiça e na injustiça um acesso original a outrem, além da ontologia heideggeriana (2015, p. 79).

Para Lévinas

é esta maneira de acolher um ente absoluto que descobrimos na justiça e na injustiça e que o discurso se efectua, ele que é essencialmente ensino. Acolhimento de outrem - o termo exprime uma simultaneidade de actividade e de passividade - que coloca a relação com o outro fora das dicotomias válidas para as coisas: do a priori e do a posteriori da actividade e da passividade (2015, p. 79).

Será a partir desse acolhimento de outrem, dessa responsabilidade, que começa a surgir a ideia de justiça em Lévinas. Conforme García (1996, p. 226), é do questionamento do mesmo pelo outro e do movimento até o outro que se dirá, em um sentido ainda pré-jurídico, que seu nome é justiça. “O outro não é aqui sujeito de Direito, como tenderia a pensar o jurista, senão uma estranha fonte de Direito".

A ideia de discurso de Lévinas aparece como uma linguagem que rompe porque é transbordante. “O dito está destinado a ser oprimido pelas possibilidades do que você pode dizer. Por trás da zona passiva do 
discurso sedimentado, codificado e fechado, surge o dizer" (GARCÍA,1996, p. 228). Para Lévinas nunca se absorve totalmente ou se esgota o dito.

Considerando o conjunto dos ensaios apresentados por Lévinas que perfazem a obra Entre Nós, o filósofo aborda o tema da justiça de forma direta em três textos: Filosofia, justiça e amor; Sobre a unicidade; e O outro, utopia e justiça. De forma indireta, já há uma compreensão sobre a ideia de justiça em De Otro Modo que Ser o Más Allá de la Essencia $(2011)^{2}$, onde o filósofo lituano faz uma aproximação da categoria à responsabilidade pelo outro. A justiça exige a contemporaneidade da representação, de maneira que

minha relação com o outro enquanto próximo confere sentido a minhas relações com todos os outros. Todas as relações humanas, enquanto humanas, provêm do desinteresse. $\mathrm{O}$ um-para-o-outro da proximidade não é uma abstração deformadora. Nela se mostra de pronto a justiça, nascida portanto da significação da significância, do um-para-o-outro da significação (LÉVINAS, 2011, p. 239).

Já em Entre Nós, Lévinas liga a justiça à ideia de responsabilidade ao argumentar que é sempre a partir do rosto, a partir da responsabilidade por outrem, que aparece a justiça (2010, p. 131). Então, a justiça aparece a partir da presença do outro, de outrem que, por si só, já nos impõe responsabilidade por ele. Aí está a justiça.

A situação cara a cara é a conjuntura privilegiada, a autêntica posição original e, precisamente, um primeiro sentido do termo (GARCÍA, 1996, p. 229). "Chamamos justiça a este acesso cara a cara, no discurso" (LÉVINAS, 2015, p. 71).

O exercício de pensar a justiça não é nada fácil, considerando que a preocupação com o justo tende a situar o pensamento em um âmbito razoável. Para tanto, o jurista deve sair de seu enclausuramento para que, assim, possa respirar (GARCÍA, 1996, p. 223).

Em Entre Nós, Lévinas reconhece que a ideia de justiça remete à ordem e também ao Estado de Direito. Começa a partir daí a defender

2 Publicada originariamente em 1974, Autrement quêetere ou au-delà de l'essence é obra imediatamente posterior à Totalidade e infinito de 1961. 
a existência de ordenação dentro do Estado, quando alega que seria impossível a relação interpessoal, havendo, pois, necessidade de limitação para as relações e para o próprio Estado. Nesse sentido, afirma Lévinas:

[...] Se não houvesse ordem de Justiça, não haveria limite para minha responsabilidade. [...] se falamos de justiça, é necessário admitir juízes, é necessário admitir instituições com o Estado; viver num mundo de cidadãos, e não só na ordem do face a face. Mas, em contrapartida, é a partir da relação com o Rosto ou de mim diante de outrem que se pode falar da legitimidade do Estado ou de sua não legitimidade. Um Estado em que a relação interpessoal é impossível, em que ela é por antecipação dirigida pelo determinismo próprio do Estado, é um Estado totalitário. Há, pois, limite para o Estado (2010, p. 132).

Ao reconhecer a necessidade do Estado de Direito e da construção de uma determinada ordem política, Lévinas não abre mão da negociação face a face entre as pessoas, ao defender que tudo o que substitui a vida humana entre os Estados não pode substituir a negociação, sendo esta absolutamente essencial (2010, p. 133).

Segundo García (1996, p. 230-231), interessa a Lévinas explorar o fio afiado da alteridade e não a retórica difusa da liberdade nem da igualdade. "O eu e o outro nada têm a ver com os personagens demasiado previsíveis do estado de natureza dos contratualistas, que rapidamente se dispõem a um pacto em proveito mútuo".

Eis o paradoxo da própria responsabilidade em Lévinas: estou obrigado sem que tal obrigação tenha começado em mim. "Escândalo para os juristas pois a lógica do Direito aparece aqui completamente transtornada. Mas este modo de responder radicalmente extracontratual não é categoria jurídica" (GARCÍA, 1996, p. 232). Aqui Lévinas se refere à própria fraternidade humana como anterior a liberdade:

A fraternidade humana tem assim um duplo aspecto, implica individualidades cujo estatuto lógico não se reduz ao estatuto de diferenças últimas num gênero; a sua singularidade consiste em cada uma se referir a si própria. [...] É preciso que a sociedade seja uma comunidade fraterna 
para estar à medida da rectidão - da proximidade por excelência - na qual o rosto se apresenta ao meu acolhimento (LÉVINAS, 2015, p. 210).

A partir dessa ideia de uma ordem política e do entendimento de que há necessidade de instituições que cuidem da autoridade política, Lévinas sustenta que o acesso ao indivíduo enquanto indivíduo humano é característico onde aquele que vem pertence à concretude do encontro, sem poder livrar-se da relação, sendo o direito reconhecido à diferença de outrem, que não é uma alteridade formal, mas alteridade do único, de forma exterior a todo o gênero (2010, p. 220).

Em Ética e Infinito, Lévinas argumentou que "é o facto da multiplicidade dos homens e a presença do terceiro ao lado de outrem que condicionam as leis e instauram a justiça" (1988, p. 81). O eu levinasiano experimenta uma relação com outrem e também com o terceiro, de forma que a relação interpessoal que o eu estabelece com outrem, também estabelece com outros homens, daí a justiça. Esta será (deve ser) exercida pelas instituições, as quais são inevitáveis, devendo ser controlada pela relação interpessoal inicial ${ }^{3}$.

Aparece, então, também em Entre Nós, a noção do terceiro, de maneira que, nesta análise da relação interpessoal que procura mostrar a significância original do direito do indivíduo na proximidade e unicidade do outro homem, não descuida do político, sendo que,

[...] para indicar como este direito original conduz ao Estado liberal, à justiça política, pela pluralidade dos indivíduos pertencentes à "extensão" do gênero humano; mas também para dizer como a referência ao rosto de outrem preserva a ética deste Estado. A multiplicidade humana não permite ao $\mathrm{Eu}$ - digo não me permite - esquecer do terceiro que me arranca da proximidade do outro: da responsabilidade anterior a todo o julgamento, da responsabilidade prejudicial a próximo, na sua imediatidade, de único e de incomparável, da socialidade original (2010, p. 221).

Segundo García, "por meio do outro se alcança — sempre tensamente — a figura nova do terceiro, que dá um giro completo à situação e acabará por acalmar introduzindo um clima de sossego. 0 terceiro não é um qualquer vindo do nada, uma referência erga omnes meramente pensada. A presença do outro é também é também presença do terceiro, de toda a humanidade que nos olha, de toda a humanidade nos olhos que me enxergam" (1996, p. 233). 
No entender de Lévinas, o terceiro, outro que é o próximo, é também meu próximo. Esta é a hora da justiça, em que há a necessidade de instituições que controlem a autoridade política. A justiça exige e funda o Estado em suas palavras, levando o humano à condição de cidadão.

Por meio do outro se alcança esta nova figura do terceiro. A presença do outro é a presença do terceiro, de toda a humanidade que nos olha, de maneira que em um plano distinto do eu e do outro, constituise o nós, que provoca uma nova inscrição das exigências éticas e que leva ao Direito (GARCÍA, 1996, p. 232).

O que Lévinas denomina de responsabilidade por outrem, ou amor sem concupiscência, significa que o eu só encontra sua exigência nele mesmo, sendo que a responsabilidade está no "eis-me-aqui" do eu, ou seja, em sua unicidade. Assim, a ordem da justiça entre os sujeitos responsáveis uns pelos outros não surge para restaurar tal responsabilidade, mas sim por causa do terceiro que é “também um outro" (2010, p. 262)4.

A experiência de abertura ao outro marca o horizonte de interesse que move o pensamento de Lévinas no que diz respeito à subjetividade. Este fato leva Hernándes (2000, p. 258) à interpretação de que o próprio pensamento de Lévinas é uma forma de empirismo, especialmente ao se situar a relação com outro ao início das reflexões levinasianas, onde o sentido e o significado começam na experiência do absolutamente exterior e heterônomo. Trata-se de um convite a voltar a pensar a noção de empirismo.

Esta é a hora da justiça, exigida pela própria caridade. É hora também das instituições que julgam e dos Estados onde as instituições se consolidam, bem como hora dos cidadãos que são iguais perante a lei. Lévinas aproxima sua ideia de justiça à ideia de responsabilidade e também de caridade, podendo-se notar um forte aspecto fenomenológico e também teológico na sua forma de entender o justo. Pois, segundo ele

\footnotetext{
Segundo explicação de Lévinas: "A unicidade me parece tomar sentido a partir da impermutabilidade que vem do eu, ou a ele é devida, na concretude de uma responsabilidade por outrem: responsabilidade que Ihe incumbiria imediatamente na própria percepção de outrem, mas como se nesta representação, nesta presença, ela já precedesse esta percepção, como se ela já estivesse aí, mais velha que o presente, e, por isso, responsabilidade indeclinável, de uma ordem estranha ao saber; como se, de toda a eternidade, 0 eu fosse o primeiro chamado a esta responsabilidade" (LÉVINAS, 2010, p. 260).
} 
é em nome da responsabilidade por outrem, da misericórdia, da bondade às quais apela o rosto do outro homem que todo o discurso da justiça se põe em movimento, sejam quais forem as limitações e os rigores do dura lex que ele terá trazido à infinita benevolência para com outrem (2010, p. 263).

No seu entendimento, Lévinas argumenta que esta é a forma de justiça necessária a uma própria excelência da democracia cujo inseparável liberalismo irá corresponder ao incessante remorso profundo da justiça. Em uma das várias entrevistas concedidas, Lévinas foi questionado acerca da questão do justo, tendo respondido que em momento algum quis excluir a justiça da ordem humana, quando, em verdade alega ter feito

uma tentativa de chegar à justiça a partir do que se pode chamar a caridade, que se mostra para mim como obrigação limitada diante do outro e, nesse sentido, acesso à sua unicidade de pessoa, e, desse modo, amor: amor desinteressado, sem concupiscência. Já disse que essa obrigação inicial, diante da multiplicidade dos seres humanos, se torna justiça. Todavia, é muito importante para mim que a justiça possa fluir, derivar da preeminência do outro (2014, p. 34-35).

Conforme García, o direito não surge como mera derivação de altas exigências morais, tampouco é mais modesto do que a moral. Alcançar o direito não significa resignar-se a cair do sublime a um território cansativo, pois o direito deve ser inventado a partir do novo espaço que abre o terceiro, espaço difícil de orientar, o qual apresenta uma dificuldade adicional que é uma matéria porosa, a alteridade radical (1996, p. 234).

Conforme a interpretação de Sybil Douek (2011, p. 197), a justiça que é de forma frequente representada por uma figura com os olhos vendados, diz-se ser cega; ou seja, "implica precisamente o esquecimento da identidade dos rostos, ou a ignorância da presença de Outrem". Dessa maneira, tal momento exige "a regulação através do nomos, da regra, da lei. Mas tal justiça, diz Lévinas, só é verdadeiramente humana, se ela atravessou a caridade e a misericórdia, isto é, se, em sua necessária cegueira, ela se abre para a santidade".

Ora, esta justiça instável está carregada de possibilidades. Ao seu lado, a temática da alteridade a situa como o outro do direito e convida a 
explorar a profunda assimetria entre justiça e direito (GARCÍA, 1996, p. 235). Surge uma justiça inesperada e intratável que desestabiliza o direito.

\section{Sobre os direitos humanos}

Além da ideia de justiça apresentada no conjunto da sua obra, Lévinas também apresentou uma noção acerca dos direitos humanos em Entre Nós, que denomina direitos do homem. Segundo ele, a descoberta dos direitos que, ante o título de direitos do homem, relacionamse à própria condição de ser homem, independente de nível social, intelectual e moral, virtudes e talentos, e a elevação destes direitos ao nível de princípios fundamentais da legislação e ordem social, marcam um momento importante da consciência ocidental (2010, p. 236).

Importante notar que, mesmo não sendo um filósofo político ou do direito, Lévinas tem plena lucidez sobre o debate acerca dos direitos humanos travado especialmente no último quarto do século XX. Ele compreende que nem sempre é fácil estabelecer uma ordem de urgência para os direitos do homem no plano concreto, podendo esta ordem variar segundo a situação de fato de cada país (2010, p. 237).

A partir daí, Lévinas defende a tese da elaboração de uma ordem humana da liberdade, por meio da eliminação de muitos obstáculos materiais do contingente e das estruturas sociais as quais perturbam e distorcem a aplicação dos direitos do homem. Ademais, o filósofo lituano entende que mesmo presente a possibilidade de concretude e expansão dos direitos do homem, ligada ao progresso científico da modernidade, "a questão da justificação ou do próprio dever ser deste direito permanece aberta" (2010, p. 237).

Uma das questões que envolvem os direitos humanos reside no debate entre o universalismo versus o relativismo destes direitos, tendo na obra de Norberto Bobbio a defesa única da proteção destes direitos e não mais de sua fundamentação filosófica. De acordo com Bobbio,

o problema que temos diante de nós não é filosófico, mas jurídico e, num sentido mais amplo, político. Não se trata de saber quais e quantos 
são esses direitos, qual é sua natureza e seu fundamento, se são direitos naturais ou históricos, absolutos ou relativos, mas sim qual é o modo mais seguro para garanti-los, para impedir que, apesar das solenes declarações, eles sejam continuamente violados (1992, p. 25).

Ao olhar o posicionamento de Lévinas dentro deste importante debate, ao que tudo indica parece que ele se inclinou no sentido de que os direitos do homem carecem de fundamento filosófico e, ainda, variam de acordo com a situação concreta de cada país. Nesse ínterim, Lévinas traça um diálogo com a filosofia de Kant no que tange à vontade livre, entendendo que o imperativo categórico seria o princípio último do direito do homem ${ }^{5}$.

Conforme Heiner Bielefeldt (2000, p. 62), a filosofia dos direitos humanos de Kant se apoia na inviolabilidade da dignidade humana e serve de parâmetro à crítica do modernismo, que não destrói o iluminismo e a modernidade. A filosofia de Kant traz a necessidade de validar a liberdade moral. A ideia de universalização do imperativo categórico se dirige à vontade de cada um, tornando-se princípio moral da capacidade de julgamento, bem como mola propulsora da ação moral. Dessa forma,

Diferentemente da legislação moral interna de cada indivíduo, que deve ser observada pela vontade de cada um, a legislação ocorre no campo da legislação institucional, porque, enquanto moralidade, permanece invisível, e não se expressa claramente com conseqüências empíricas, o Direito faz parte da realidade empírica. Para ser legítima, concomitantemente, é ligada a uma idéia jurídica inteligível que deve ser representada, isto é, apresentada indiretamente na legislação e nas instituições legislativas estatais (BIELEFELDT, 2000, p. 92)

Talvez a aproximação de Lévinas à filosofia de Kant resida no interesse daquele em defender a vontade livre enquanto responsabilidade por outrem, responsabilidade infinita e mediação ontológica,

De acordo com Kant, "o imperativo categórico é, portanto, único e pode ser descrito da seguinte forma: age só segundo máxima tal que possas a mesmo tempo querer que ela se torne lei universal" (KANT, 2004, p. 51). 
onde o para-o-outro é o próprio desígnio do humano. Por isso a justiça se origina nos relacionamentos face a face.

Em passagem na Fundamentação da Metafísica dos Costumes, Kant argumenta que:

[...] quando nos julgamos livres, incluimo-nos no mundo inteligível como seus membros e reconhecemos a autonomia da vontade, juntamente com sua conseqüência, a moralidade; mas se nos julgamos obrigados, consideramo-nos como pertencentes ao mundo sensível e, contudo, simultaneamente, também ao mundo inteligível (2004, p. 85-86).

Neste fragmento Kant está a demonstrar que o ser humano tem que ser concebido a partir de dois pontos de vista e não podemos pensar um sem o outro; isto é, a autonomia da vontade (liberdade) e a legalidade instituída pelo Estado. Immanuel Kant foi o filósofo que propôs o paradoxo da obrigação ética realizado como performance da liberdade. No entanto, conforme aponta Douzinas (2009, p. 360), a coordenação de livre-arbítrios e sujeitos no reino dos fins kantiano, do qual a lei de direitos humanos é uma aproximação secular, acaba por suprimir, de forma geral, o dever ético em relação ao outro.

Já em Lévinas, o direito deve ser pensado a partir da nova formulação do terceiro, o que só pode ser executado a partir de uma proposta de alteridade. Na filosofia de Lévinas, razão prática e razão teórica se encontram. A partir daí "a temática da alteridade acaba por situar a justiça como o outro do Direito e convida a explorar a profunda assimetria entre justiça e Direito" (GARCÍA, 1996, p. 235).

Por isso, as reivindicações de direitos manifestam a capacidade do homem de transcender limites contextuais instaurados no exercício de interesses e direitos, redefinindo conceitos e fronteiras. Ao mesmo tempo, diz Douzinas, o direito expressa e pressupõe uma comunidade de deveres para outros em sua singularidade. Ao lado da comunidade de relações externas entre sujeitos antagônicos, existe outra comunidade, qual seja a comunidade de amor e proximidade, onde o Eu se volta ao outro. A comunidade de direitos humanos, dessa maneira, constitui uma comunidade de reféns do outro. 
No perceber de Benjamin Hutchens (2007, p. 144-145), Lévinas entende que a democracia não seria a justiça ela mesma, mas ela pode melhorar a justiça por meio da criação de leis que servem para melhorar a legislação, encorajando a excelência ética. Dessa forma, a justiça tem sua origem na proximidade dentro dos relacionamentos face a face. Ainda que a justiça preceda a responsabilidade, seu estabelecimento se dá unicamente no face a face (p. 147).

Especificamente, em relação à interpretação levinasiana acerca dos direitos humanos, García entende que Lévinas necessita dar um sentido próprio aos célebres direitos humanos. No debate filosóficojurídico, estamos acostumados a ver nos direitos humanos princípios e verdades ideais, a lógica do universal e do particular. No entanto, "é prioritário semear a lógica do outro, da diferença radical, para o qual os direitos humanos estão tão bem dotados. Seu fundamento não pode ser o conceito de homem senão de outro. Os direitos humanos aparecem assim como direitos ante tudo, do outro homem" (1996, p. 238).

Eis a nova e significativa leitura da concepção ocidental dos direitos humanos. Tais direitos, na leitura de Lévinas, são exigências além da justiça. Por isso, a partir dos direitos humanos existem poderes infinitos que trazem bens imprevisíveis, exterioridade que acaba por manifestar a necessidade de pensar o infinito a partir do desconhecido.

Nas palavras de Lévinas,

Esta inversão humana do em-si e do para-si, do "cada um por si", em um eu ético, em prioridade do para-outro, esta substituição ao para-si da obstinação ontológica de um eu doravante decerto único, mas único por sua eleição a uma responsabilidade pelo outro homem - irrecusável e incessível - esta reviravolta radical produzir-se-ia no que chamo encontro do rosto de outrem (2010, p. 242).

O problema de uma nova ordem sócio-política reside na necessidade de um Estado além do Estado, pois se exige, além de suas instituições, a legitimidade, mesmo que seja transpolítica, como a busca e a defesa dos direitos do homem. Então, para além da justiça, deverão ser acrescidos recursos de caridade a partir da unicidade humana em cada um dos cidadãos reunidos em nação (LÉVINAS, 2010, p. 243). 
Dessa forma, as instituições da justiça são, por certo, necessárias, no entanto, são secundárias e derivadas do mandato original do rosto e da sensibilidade vulnerável do sujeito. Neste contexto, a solidariedade seria anterior e superior a justiça, porquanto acontece em um tempo imemorial da sensibilidade (PALACIO, 2015, p. 43).

\section{Direitos humanos e solidariedade}

A partir da filosofia de Lévinas instaura-se um novo humanismo, cuja consequência quanto ao reconhecimento dos direitos humanos fundamentais reside no fato de serem ditados pela própria alteridade do outro, que é fundamento e dimensão teleológica da justiça (SIDEKUM, 2006, p. 527).

Os direitos humanos passam a ser vistos a partir de um novo paradigma pelo pensamento levinasiano, o qual, no dizer de Sidekum, exige uma fidelidade hermenêutica que implica numa transparadigmatização das categorias utilizadas no contexto de seu novo humanismo.

A justiça, para Lévinas,

acontece concretamente quando a lei que responsabiliza o meu Eu ultrapassando todas as formalidades jurídicas essenciais e colocando a minha subjetividade além do questionamento dos direitos humanos adquiridos, porém, no evento histórico, o tempo do outro, que se conta diante da absoluta responsabilidade que me cabe nessa relação assimétrica para com o Outro (SIDEKUM, 2006, p. 528).

O outro permanece transcendente, é infinito, e me convoca à responsabilidade por ele. Nesse contexto, dois argumentos surgem ante a filosofia dos direitos, segundo Douzinas: o primeiro é o fato de que os direitos existem somente em relação a outros direitos, e, segundo, as reivindicações de direitos envolvem o reconhecimento de outros e de seus direitos (2009, p. 349).

Torna-se, assim, curioso o fato de que os direitos humanos existem mesmo antes de terem sido promulgados e detêm certa independência em relação ao contexto de seu aparecimento, sempre mantendo 
uma distância crítica da lei. Os direitos também possuem em sua essência a possibilidade de suspensão de qualquer referência a tempo e lugar. Se já em Heidegger foi possível notar que o Eu não é constituído senão em relação aos outros, não existe vida que não seja vida com outros, de maneira que

se meu direito tem significado apenas em relação a outro direito, cuja ação ou prerrogativa estão pressupostos no reconhecimento ou exercício do meu direito, o direito do Outro sempre e já precede o meu. O (direito do) Outro vem primeiro; antes do meu direito e antes da minha identidade conforme organizada pelos direitos, vem minha obrigação, minha virada radical em direção à exigência de respeitar a integridade existencial do Outro (DOUZINAS, 2009, p. 353).

É importante notar que para Lévinas, contrariando a filosofia moral da modernidade (Kant), a demanda não depende da razão absoluta ou da lei universal, mas do concreto encontro histórico e empírico com o outro. Para Douzinas (2009, p. 357-358), “os direitos humanos representam, portanto, concretizações do direito da outra pessoa e do meu dever, e minha liberdade, antes de se tornar uma antagônica à de outros, é a liberdade da responsabilidade e da fraternidade". A moralidade não é sinônimo de direitos humanos e não deriva deles. A responsabilidade ética precede os direitos, garantindo-lhes legitimidade.

É, pois, a experiência de abertura ao outro que marca o horizonte de interesse sobre a subjetividade e sobre a filosofia dos direitos humanos de Lévinas. O humanismo radical do outro ser humano aparece enquanto novo paradigma humano, um humanismo também político.

Um humanismo dito, político, do outro homem revela a inimaginabilidade do rosto de toda a humanidade e a dignidade da humanidade em cada face. No atual contexto global, isso significa a busca de paradigmas democráticos, envoltos na revolta ética de Lévinas, orientados para a ação da sociedade civil (EISERMANN, 2008, p. 326). Para Eisermann, nesta mudança,

a ética e a política, a responsabilidade e a justiça são despedaçadas em sua ordem religiosa ontológica e dicotômica, sem abandonar seu 
retorno à ordem original da lei e, finalmente, divididas no terceiro, que agora tem seu próprio nome: a solidariedade (EISERMANN, 2008, p. 327).

O acordo entre iguais sempre se refere ao valor ético da solidariedade. A solidariedade fortalece e compromete o indivíduo, e com ele, toda a comunidade. A solidariedade é a responsabilidade inalienável de buscar justiça para as pessoas. Os direitos humanos, assim, são direitos das pessoas que vivem e morrem à sombra da globalização, enquanto que o reconhecimento da dignidade humana deve ser decisiva e concretamente ocorrer (EISERMANN, 2008, p. 329-330).

Frente à profunda assimetria entre justiça e direito, ou entre a justiça e os direitos humanos, a filosofia do direito, recorrendo ao pensamento de Lévinas, encontra a lógica da justiça subordinada à lógica da solidariedade, pois o rosto significa pra mim uma responsabilidade irrecusável antecedente ao próprio consentimento de liberdade, da mesma forma que a todo pacto ou contrato.

\section{Considerações finais}

A partir da presente pesquisa, podem-se apontar alguns aspectos importantes presentes na filosofia de Emmanuel Lévinas, cuja análise se torna de suma importância para a atual reflexão da filosofia do direito no que diz respeito à teoria da justiça e aos direitos humanos.

Nesse contexto, podem-se apontar as seguintes notas conclusivas:

4.1 - Emmanuel Lévinas mesmo não possuindo, de forma específica, uma filosofia política e do direito consegue oferecer uma profunda reflexão acerca da justiça e dos direitos humanos a partir de conceitos-chave de seu pensamento, tais como responsabilidade, caridade, outro, rosto.

4.2 - A influência da fenomenologia tanto de Husserl quanto de Heidegger em sua filosofia demonstra-se, também (mas não só), a partir da adoção que Lévinas faz da ideia de horizonte, onde irá desenvolver a noção de infinito ante o desejo. Desejo de outrem!

4.3 - Em seus escritos, a justiça aparece ligada à ideia de responsabilidade, pois é sempre a partir do rosto, da responsabilidade por 
outrem, que aparece a justiça. A presença do outro de outrem por si só já nos impõe responsabilidade por ele. Aí está a justiça.

4.4 - Há o reconhecimento por parte da sua filosofia da existência de uma ordem dentro do Estado de Direito, que o pensador lituano denomina, em várias passagens, de Estado Liberal. Em que pese tal reconhecimento, diferentemente dos contratualistas da modernidade, Lévinas não faz concessão quanto à relação face a face, cuja ordem requer também minha responsabilidade pelo terceiro. Daí ser a própria justiça que exige e funda o Estado.

4.5 - Lévinas inverte a lógica de direitos humanos, que ele denomina de direito do homem, numa conotação mais jusnaturalista do que dogmática, mormente quando os direitos humanos são direitos do outro homem.

4.6 - Qual é o legado da filosofia social e jurídica de Emmanuel Lévinas? Esta é uma pergunta que suporta várias respostas a partir de ângulos diferentes. No entanto, dentro dos objetivos da presente pesquisa, pode-se concluir que ante a reflexão hermenêutico-fenomenológica de sua filosofia, cuja categoria epistemológica fundamental é a compreensão e a meta é a interpretação dos conceitos, Lévinas demonstrou que a teoria da justiça ainda pode ser pensada a partir de uma proposta de alteridade radical, profunda, de desejo infinito pelo outro, em total desapego às teorias liberais igualitárias, sistêmicas e do discurso. Emmanuel Lévinas põe em xeque a força do contratualismo para o Estado de Direito e aposta na responsabilidade e na caridade humanas pelo outro, ou seja, dever moral que não inicia no agente, mas fora dele, ao contrário da filosofia de Kant.

Se as obras de Husserl e de Heidegger apresentaram significativa importância para o desenvolvimento das teorias hermenêuticas ao longo do século XX, influenciando, principalmente a filosofia de HansGeorg Gadamer, cujas contribuições ao Direito são amplamente positivas e satisfatórias, tem-se na Filosofia de Lévinas uma nova contribuição fenomenológica, não referente à interpretação da lei, mas sim à compreensão do outro. Eis um novo aporte hermenêutico para pensar a teoria da justiça no século XXI. 


\section{Referências}

BIELEFELDT, H. Filosofia dos direitos humanos. Trad. Dankwart Bernsmuller. São Leopoldo: Ed.UNISINOS, 2000.

BOBBIO, N. A era dos direitos. Trad. Carlos Nelson Coutinho. Rio de Janeiro: Elsevier, 1992.

DOUEK, S. S. Paul Ricoeur e Emmanuel Lévinas: um elegante desacordo. São Paulo: Edições Loyola, 2011.

DOUZINAS, C. O fim dos direitos humanos. Trad. Luzia Araújo. São Leopoldo: Unisinos, 2009.

EISERMANN, M. Globalisierung im Grundriss von Menschenrecht und Menschenwürde. In: FABRI, M.; FARIAS, A. B.; SOUZA, R. T. Alteridade e ética: obra comemorativa dos 100 anos de nascimento de Emmanuel Levinas. Porto Alegre: EDIPUC, 2008. p. 309-332.

GARCÍA, J. I. M. La justicia paradójica de Emmanuel Lévinas. Anuário de Filosofía del Derecho, España, Estudios, v. XIII, n. 13-14, p. 221-240, 1996.

HEIDEGGER, M. El ser y el tiempo. Trad. José Gaos. México: Fondo de Cultura Económica, 2000.

HERNÁNDES, F. J. H. Alteridad e infinito: la substitución en Levinas. Cuadernos Salmantinos de Filosofia, Salamanca, v. XXVII, p. 243-277, 2000.

HUTCHENS, B. C. Compreender Lévinas. Trad. Vera Lúcia Mello Joscelyne. Petrópolis: Vozes, 2007.

KANT, I. Fundamentação da metafísica dos costumes e outros escritos. Trad. Leopoldo Holzbach. São Paulo: Martin Claret, 2004.

LÉVINAS, E. De otro modo que ser o más allá de la essencia. Trad. Antonio Pintor Ramos. Salamanca: Ediciones Sígueme, 2011.

LÉVINAS, E. Entre nós: ensaios sobre a alteridade. Trad. Pergentino Stefano Pivatto. Petrópolis: Vozes, 2010. 
LÉVINAS, E. Ética e infinito. Diálogos com Philippe Nemo. Trad. João Gama. Lisboa: Edições 70, 1988.

LÉVINAS, E. Humanismo do outro homem. Trad. Pergentino S. Pivato et all. Petrópolis: Vozes, 2012.

LÉVINAS, E. Totalidade e infinito. Trad. José Pinto Ribeiro. Lisboa: Edições 70 Ltda., 2015.

LÉVINAS, E. Violência e rosto. Trad. Fernando Soares Moreira. São Paulo: Edições Loyola, 2014.

PALACIO, M. La vulnerabilidad fundando la ética de la solidariedad y la justicia. Análisis. Revista de Investigación filosófica, Zaragoza, v. 2, n. 1, p. 29-47, 2015. SIDEKUM, A. LEVINAS, Emmanuel, 1905-1995. In: BARRETO, V. P. (Coord.). Dicionário de filosofia do direito. Rio de Janeiro: Renovar; São Leopoldo: UNISINOS, 2006.

Recebido: 29/12/2017

Received: $12 / 29 / 2017$

Aprovado: 09/02/2018

Approved: 02/09/2018 